\title{
Pediatric nonalcoholic fatty liver disease associated with craniopharyngioma: case report and review of the literature
}

\author{
Manel Jemel ${ }^{1 *}$, Ines Khochtali ${ }^{1}$, Hanene Sayadi ${ }^{1}$ and Mondher Golli ${ }^{2}$ \\ ${ }^{1}$ Department of internal medicine, endocrinology unit. Monastir University Hospital, Tunisia \\ ${ }^{2}$ Department of Radiology. Monastir University Hospital, Monastir, Tunisia
}

\begin{abstract}
Nonalcoholic fatty liver disease (NAFLD) is a multicluster disease which ranges from simple steatosis to non-alcoholic steatohepatitis NASH. Recently it becomes the main cause of chronic liver disease in children and has emerged to be predicted by many specific risk factors, such as obesity and sedentary lifestyle, on predisposing genetic settings. The natural history of pediatric NAFLD is lacking, and the etiopathogenesis is not fully understood. It has been reported that children with craniopharyngioma can have features of metabolic syndrome and other comorbidities. We reported the case of a 11-year-old child who was diagnosed with craniopharyngioma. After the surgery of his brain tumor and hormone replacement therapy he was diagnosed as having NAFLD.
\end{abstract}

We will use this case to highlight the main pathophysiologic processes resulting in the development of NAFLD in children following treatment of craniopharyngioma. We try to focus on the endocrine disturbances that can link the two entities.

\section{Introduction}

Nonalcoholic fatty liver disease (NAFLD) represents a broad clinical spectrum ranging from simple fatty liver an early reversible liver fat accumulation, to nonalcoholic steatohepatitis (NASH), which may progress to liver fibrosis, cirrhosis and hepatocellular carcinoma [1].

During the last decade, pediatric NAFLD has emerged as the main cause of chronic liver disease in children [2]. Increasing prevalence is thought to result from a combination of several environmental and genetic factors [3]. A few case reports have described the development of NAFLD in children with craniopharyngioma $[4,5]$.

\section{Case report}

A 11-year-old male presented with complaints of sudden diminution of vision in the left eye and occasional headaches in the context of stunted growth. Magnetic resonance imaging (MRI) showed the sellar and suprasellar mass displaying a heterogeneous signal due to the presence of cystic, solid and calcic components which are characteristic features of a craniopharyngioma. The lesion was compressing the optic chiasm, the mamillary body and the pituitary gland as well as branches of polygon of Willis (Figures 1,2).

Hormonal exploration has found a central hypothyroidism and hyperprolactinemia due to functional Pituitary Stalk disconnection. The ACTH stimulation test showed a corticotrop deficiency.

The patient was operated through in front with complete resection of a suprasellar cystic tumor containing calcifications. The pituitary stalk was invaded by the tumor, so it was sacrificed.

Six months after surgery, the child presented a rapid weight gain with a body mass index at $32 \mathrm{~kg} / \mathrm{m}^{2}$, greater than $95^{\text {th }}$ percentile. The waist circumference was at $104 \mathrm{~cm}$. The biological data found of diabetes insipidus, so he was treated with antidiuretic hormone therapy.
Besides, hormonal exploration showed corticotropic adrenal gland insufficiency, growth hormone deficiency and hypothyroidism, for which a hormone replacement therapy was started.

The liver function tests showed elevated serum alanine aminotransferase without cholestasis. On abdominal ultrasound, there was hepatomegaly with diffuse homogeneous increased parenchymal echogenicity secondary to diffuse fatty liver infiltration.
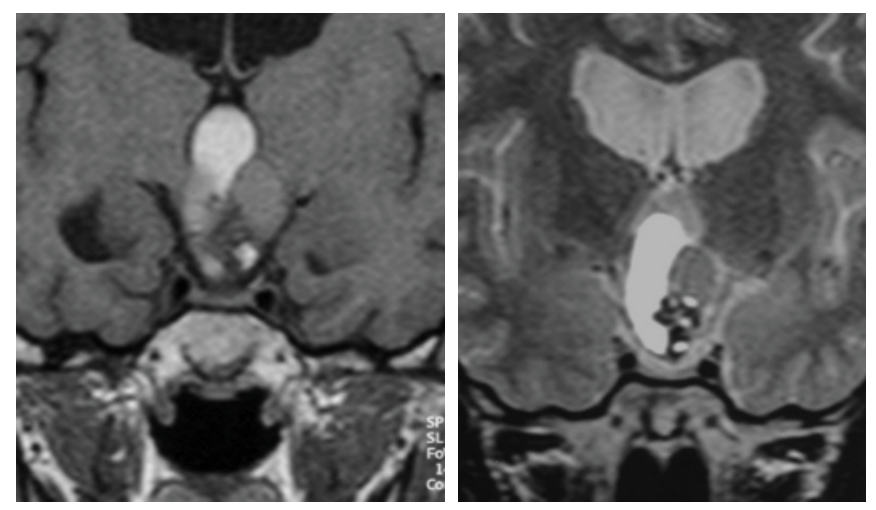

Figures 1,2. T1 and T2 coronal MRI weighted images showing the sellar and suprasellar mass displaying a heterogeneous signal due to the presence of cystic, solid and calcic components which are characteristic features of a craniopharyngioma.

Correspondence to: Manel Jemel, Department of internal medicine, endocrinology unit. Monastir University Hospital 5000, Tunisia; Tel 00216 20139710; E-mail: Maneljemel@gmail.com

Key words: craniopharyngioma, nonalcoholic fatty liver disease, hypothalamic obesity, hypopituitarism, GH deficiency.

Received: August 27, 2017; Accepted: September 25, 2017; Published: September 28, 2017 
Hepatitis B and C has been ruled out by serology tests, which returned negative.

The patient and the family members confirmed that the patient had no alcohol intake habit. He had no history of blood transfusion, drug abuse, or hypertension.

Viral hepatitis, autoimmune liver disease, iron overload, and metabolic liver disorders were all excluded.

Nonalcoholic fatty liver disease has been diagnosed.

\section{Discussion}

The craniopharyngioma, is the most common neoplasm of the hypothalamic-pituitary area in childhood accounting for approximately $80 \%$ of tumors in this location and represents $5-15 \%$ of intracranial tumors [6].

Histologically it is a benign tumor with high overall survival rates. Nonetheless, it is associated with considerable morbidity. The presence of a craniopharyngioma, and/or treatment related damage to centers in the hypothalamus often results in hypothalamic obesity (HO), insulin resistance with subsequent development of NAFLD. This may be exacerbated by hormonal deficits from coexistent hypopituitarism. These disorders are becoming increasingly recognized, and our understanding of the mechanisms underlying the association craniopharyngioma and NAFLD has progressed [7].

\section{Craniopharyngioma and hypothalamic obesity}

The hypothalamus is known to be the master gland of regulating weight, fat storage and energy expenditure. Structural damage of the hypothalamus, radiotherapy or the resection of a brain tumor can lead to the disturbances of this equilibrium, resulting in hypothalamic obesity $(\mathrm{HO})$ [8-10]. Weight gain could be a sign of hypothalamic involvement leading, together with other symptoms, to the diagnosis of craniopharyngioma. In a large study of 63 children, $17 \%$ had a history of significant weight gain in the 3.5 years before the diagnosis of craniopharyngioma [11]. However, in the presented case, although the patient's tumor appeared to involve the hypothalamus at diagnosis, he had no evidence of pre-operative HO. In fact, prior to craiopharyngioma resection he had under growth (-3 DS) which may have been a consequence of GH deficiency.

After tumor resection, survivors of childhood craniopharingioma experienced an about $50 \%$ increased rate of obesity $[12,13]$. The strongest weight gain occurs during the first 12 months following surgery [14]. In a study conducted in the St. Jude Children's Research Hospital, 65\% of 55 patients treated for craniopharyngioma during childhood (about $90 \%$ surgery plus radiotherapy) were found overweight or obese after 7.6 years (range 5-21.3 years) from diagnosis [15].

Muller showed that the extension of the tumor to the hypothalamus was found in $76 \%$ of obese and $96 \%$ of severely obese patients compared to $33 \%$ of normal weight survivors [16].

The main risk factors recognized for severe obesity include large hypothalamic tumors or lesions affecting several medial and posterior hypothalamic nuclei that impact satiety signaling pathways [17]. Recently, Roth et al. prove that the development of diabetes insipidus had been identified as an endocrine marker for increased HO risk (14). In our case, a rapid weight gain was noted within 6 month after tumor resection.

\section{Etiology of hypothalamic obesity and related NAFLD}

The mechanisms contributing to hypothalamic obesity in craniopharyngioma, likely include one or more of the following dysfunctions, such as hyperleptinemia, hyperinsulinemia, reduced SNS tone, dysregulation of $11 \beta$-hydroxysteroid dehydrogenase 1 $(11 \beta-H S D 1)$ and melatonin, and a decreased basal metabolic rate [18].

\section{Hyperleptinemia}

Leptin mainly expressed by adipose tissue, has a key role in the regulation of food intake and energy expenditure [19,20].

Guran $\mathrm{T}$ et al have shown that leptin levels corrected for body mass index (BMI) are higher in patients with hypothalamic obesity than in simple obesity, indicating that there a disruption of responses to leptin and more severe leptin resistance in hypothalamic obesity [21]. A disturbed feedback mechanism from the hypothalamic leptin receptors to the adipose tissue can be assumed, including a loss of leptin feedback inhibition on neuropeptide Y and Agouti-related peptide which are orexigenic hormones [21]

Hyper secretion resulting from hypothalamic damage and defect in neuralregulation of the $\beta$-cells has been proposed as a possible mechanism [21].

\section{Dysregulation of the SNS}

SNS is a main determinant of the metabolic rate of adipose tissue by fat mobilization and thermogenesis. Thus, dysregulation of the SNS in hypothalamic obesity can lead to a reduction in the basal metabolic rate. Recent data has shown that hypothalamic obesity patients with craniopharyngioma have decreased urinary homovanillic acid and vanillylmandelic acid, indicating reduced sympathetic tone [22].

It seems unlikely that the SNS participate in fat accumulation in the liver, but many studies suggest a pivotal role of SNS in modulating the fibrogenic function of Hepatic Stellate Cells (HSC) . A relevant findings suggests that HSC express key enzymes for catecholamine biosynthesis and use them to autoregulate their growth, and express functional adrenoceptors wich are implicated in the pathogenesis of hepatic inflammation and fibrogenesis $[23,24]$.

In the other hand mice with genetic deletion of dopamineb-hydroxylase, lacking cathecholamines, are poorly fibrogenic [23] Emerging evidence have shown here that hHSC express adrenoreceptors, which are markedly upregulated in human livers with NAFLD cirrhosis [25].

Suggesting therefore that adrenergic antagonists may be novel antifibrotic agents in NAFLD.

In HO the dysfunction of SNS can be a protective factor to avoid the fibrosis process.

\section{Dysregulation of $11 \beta$-hydroxysteroid dehydrogenase 1 (11 $\beta$-HSD1):}

$11 \beta$-HSD1 converts inactive glucocorticoids to active glucocorticoids (GC). Tt is expressed in several organs, such as the liver and adipose tissue. A study showed that the urinary free and conjugate cortisol/cortisone and their metabolites (11-OH/11-oxo) were significantly high in patients with hypothalamic obesity, and this ratio showed a significant correlation with the ratio of visceral fat/ subcutaneous fat [26]. 
These results demonstrated enhanced cortisone-to-cortisol conversion in hypothalamic obesity and imply that the hypothalamus conveys a signal to the peripheral circulatory system, which modulates its $11 \beta$-HSD1.

GC are well recognizes to be a cause of NAFLD. The liver-specific disruption of glucocorticoid receptor (GR) action improves the steatotic phenotype in fatty liver mouse models [27].

In the other hand the pre-receptor regulation of GC action can also regulate hepatic phenotype. Genetic knockdown of 11b-HSD1 [28] as well as pharmacological inhibition were effective in reducing steatosis, [29] suggesting that the inhibition of $11 \beta$-HSD1 can improve the hepatic lipid levels.

\section{Melatonin}

Melatonin is a neuroendocrine hormone, which is primarily synthesized by the pineal, is secreted during the hours of darkness and influences the circadian rhythm. Since sleep regulation and circadian rhythms are partially mediated by hypothalamic structures, sleep disturbance is shown in patients with childhood craniopharyngioma [30]. Increased daytime sleepiness is related to decreased nocturnal melatonin levels, and nocturnal melatonin levels have been related to the degree of obesity in patients with craniopharyngioma) [31].

Recently, research has focused on the roles of melatonin in liver fat accumulation. Animal experiments showed melatonin exerts protective effects against fatty liver in rats induced by high-fat diet. Melatonin reduced hepatic steatosis and inflammation by lowering serum AST, ALT, liver total cholesterol, and triglycerides in high-fat diet fed rats [32]. Further studies have suggested that melatonin can decrease hepatocyte apoptosis [33].

The induction of nonalcoholic steatohepatitis in rats feeding by Methionine and choline-deficient diet found a reduction in NAFLD phenotype in rats treated with melatonin $(50 \mathrm{mg} / \mathrm{kg} / \mathrm{day}$, intraperitoneally) It was observed that melatonin decreased oxidative stress, levels of proinflammatory cytokines, and hepatocyte apoptosis.

A study on high-fat-diet rats by Gregorios Hatzis et al. [34] found that compared to untreated group melatonin can attenuate oxidative stress, lessen liver damage, and improve liver histology in rats with high fat diet-induced NAFLD, when given concurrently with the diet. These results were confirmed by other study $[35,36]$. Others demonstrated the effect of melatonin on patients with NAFLD [35]. Essentiale with tryptophan $(2 \times 500 \mathrm{mg} /$ day $)$ or melatonin $(2 \times 5 \mathrm{mg} /$ day $)$ for 14 months both have a significant reduction in the activity of gammaglutamyl transferase (GGPT) and levels of triglycerides and LDL-cholesterol comparing with the control group treated with Essentiale forte only. In the liver biopsies performed before and after treatment, melatonin and tryptophan reduced macrovesicular steatosis and lobular inflammation, while there was no change in control group in oxidative stress, lipid metabolism, and hepatic steatosis and its potential therapeutic roles. Animal experiments showed that melatonin was ineffective in reversing established steatosis. But melatonin attenuates high fat diet-induced fatty liver disease in rats [32,34].

\section{Decreased basal metabolic rate}

While many patients report hyperphagia [37], recent studies have also reported an overall decrease in energy intake in patients with $\mathrm{HO}$ compared with controls [38,39].

Reduction in energy intake is offset by greater relative decrease in basal metabolic rate and physical activity related energy expenditure in HO patients. This hypothesis might explain in part why weight loss attempts through caloric restriction and exercise has been largely unsuccessful [40].

\section{Conclusion}

The presence of a craniopharyngioma, and/or treatment related damage to centers in the hypothalamus that regulate energy balance often results in severe obesity and abnormal eating behaviors. This may be exacerbated by hormonal deficits from coexistent hypopituitarism. The HO may be the main cause of NAFLD, but the specific disruptions in $\mathrm{HO}$ can major or attenuate the liver fat accumulation or the progression of fibrogenesis process in NAFLD. Along with the increased understanding of the relationship between HO and NAFLD can help to develop new pharmacologic concepts.

\section{References}

1. Law K, Brunt EM (2010) Nonalcoholic fatty liver disease. Clin Liver Dis 14: 591-604 [Crossref]

2. Day CP (2011) Non-alcoholic fatty liver disease: a massive problem. Clin Med (Lond) 11: 176-178. [Crossref]

3. Day CP (2010) Genetic and environmental susceptibility to non-alcoholic fatty liver disease. Dig Dis 28: 255-260. [Crossref]

4. Altuntå̊Ÿ B, OzÃßakar B, Bideci A, Cinaz P (2002) Cirrhotic outcome in patients with craniopharyngioma. J Pediatr Endocrinol Metab 15: 1057-1058. [Crossref]

5. Adams LA, Feldstein A, Lindor KD, Angulo P (2004) Nonalcoholic fatty liver disease among patients with hypothalamic and pituitary dysfunction. Hepatology 39: 909-914. [Crossref]

6. May JA, Krieger MD, Bowen I, Geffner ME (2006) Craniopharyngioma in childhood Adv Pediatr 53: 183-209. [Crossref]

7. Adams LA, Feldstein A, Lindor KD, Angulo P (2004) Nonalcoholic fatty liver disease among patients with hypothalamic and pituitary dysfunction. Hepatology 39: 909-914. [Crossref]

8. Lee M, Korner J (2009) Review of physiology, clinical manifestations, and managemen of hypothalamic obesity in humans. Pituitary 12: 87-95. [Crossref]

9. Vinchon M, Weill J, Delestret I, Dhellemmes P (2009) Craniopharyngioma and hypothalamic obesity in children. Childs Nerv Syst 25: 347-352. [Crossref]

10. Ahmet A, Blaser S, Stephens D, Guger S, Rutkas JT, et al. (2006) Weight gain in craniopharyngioma--a model for hypothalamic obesity. J Pediatr Endocrinol Metab 19: 121-127. [Crossref]

11. Fournier A, Pauli A, Cécile JP, Cousin J, Decherf A (1968) [Craniopharyngioma having the appearance of an isolated obesity]. J Sci Med Lille 86: 171-175. [Crossref]

12. Müller HL, Emser A, Faldum A, Bruhnken G, Etavard-Gorris N, et al. (2004) Longitudinal study on growth and body mass index before and after diagnosis of childhood craniopharyngioma. J Clin Endocrinol Metab 89: 3298-3305. [Crossref]

13. Müller HL, Bueb K, Bartels U, Roth C, Harz K, et al. (2001) Obesity after childhood craniopharyngioma--German multicenter study on pre-operative risk factors and quality of life. Klin Padiatr 213: 244-249. [Crossref]

14. Roth CL, Eslamy H, Werny D, Elfers C, Shaffer ML, et al. (2015) Semiquantitative analysis of hypothalamic damage on MRI predicts risk for hypothalamic obesity. Obesity 23: 1226-1233. [Crossref]

15. Crom DB, Smith D, Xiong Z, Onar A, Hudson MM, et al. (2010) Health status in long-term survivors of pediatric craniopharyngiomas. $J$ Neurosci Nurs 42: 323-328. [Crossref]

16. Müller HL, Gebhardt U, Etavard-Gorris N, Korenke E, Warmuth-Metz M, et al. (2004) Prognosis and sequela in patients with childhood craniopharyngioma--results of HITENDO and update on KRANIOPHARYNGEOM 2000. Klin Padiatr 216: 343-348. [Crossref]

17. Roth L (2015) Hypothalamic Obesity in Craniopharyngioma Patients: Disturbed Energy Homeostasis Related to Extent of Hypothalamic Damage and Its Implication for Obesity Intervention Christian. J Clin Med 4: 1774-1797. [Crossref]

18. Kim JH, Choi JH (2013) Pathophysiology and clinical characteristics of hypothalamic obesity in children and adolescents. Ann Pediatr Endocrinol Metab 18: 161-167. [Crossref] 
19. Jéquier E (2002) Leptin signaling, adiposity, and energy balance. Ann N Y Acad Sci 967: 379-388. [Crossref]

20. Schwartz MW, Woods SC, Porte D Jr, Seeley RJ, Baskin DG (2000) Central nervous system control of food intake. Nature 404: 661-671. [Crossref]

21. Guran T, Turan S, Bereket A, Akcay T, Unluguzel G et al. (2009) The role of leptin, soluble leptin receptor, resistin, and insulin secretory dynamics in the pathogenesis of hypothalamic obesity in children. Eur J Pediatr 168: 1043-1048. [Crossref]

22. Roth CL, Hunneman DH, Gebhardt U, Stoffel-Wagner B, Reinehr T, et al. (2007) Reduced sympathetic metabolites in urine of obese patients with craniopharyngioma. Pediatr Res 61: 496-501. [Crossref]

23. Oben JA, Roskams T, Yang S, Lin H, Sinelli N, et al. (2004) Hepatic fibrogenesis requires sympathetic neurotransmitters. Gut 53: 438-445. [Crossref]

24. Sancho-Bru P, Bataller R, Colmenero J, Gasull X, Moreno M. et al. (2006) Norepinephrine induces calcium spikes and proinflammatory actions in human hepatic stellate cells. Am J Physiol Gastrointest Liver Physiol 291: G877-G884. [Crossref]

25. Oben JA, Yang S, Lin H, Ono M, Diehl AM (2003) Norepinephrine and neuropeptide Y promote proliferation and collagen gene expression of hepatic myofibroblastic stellate cells. Biochem Biophys Res Commun 302: 685-690. [Crossref]

26. Tiosano D, Eisentein I, Militianu D, Chrousos GP, Hochberg Z (2003) 11 betaHydroxysteroid dehydrogenase activity in hypothalamic obesity. J Clin Endocrinol Metab 88: 379-384. [Crossref]

27. Lemke U, Krones-Herzig A, Berriel Diaz M, Narvekar P, Ziegler A, et al. (2008) The glucocorticoid receptor controls hepatic dyslipidemia through Hes1. Cell Metab 8: 212 223. [Crossref]

28. Li G, Hernandez-Ono A, Crooke RM, Graham MJ, Ginsberg HN (2011) Effects of antisense-mediated inhibition of 11ß-hydroxysteroid dehydrogenase type 1 on hepatic lipid metabolism. J Lipid Res 52: 971-981. [Crossref]

29. Sakamuri PSS, Sukapaka M, Prathipati VK, Nemani H, Putcha UK, et al. (2012) Carbenoxolone treatment ameliorated metabolic syndrome in WNIN/Ob obese rats, but induced severe fat loss and glucose intolerance in lean rats. PLoS One 7: e50216.

30. Müller HL (2010) Increased Daytime Sleepiness in Patients with Childhood Craniopharyngioma and Hypothalamic Tumor Involvement: Review of the Literature and Perspectives. Int J Endocrinol 519607. [Crossref]
31. Müller HL, Handwerker G, Wollny B, Faldum A, Sörensen N (2002) Melatonin secretion and increased daytime sleepiness in childhood craniopharyngioma patients. $J$ Clin Endocrinol Metab 87: 3993-3996. [Crossref]

32. Pan M, Song YL, Xu JM, Gan HZ (2006) Melatonin ameliorates nonalcoholic fatty liver induced by high-fat diet in rats. J Pineal Res 41: 79-84. [Crossref]

33. Tahan V, Atug O, Akin H, Eren F, Tahan G, et al. (2009) Melatonin ameliorates methionine- and choline-deficient diet-induced nonalcoholic steatohepatitis in rats. $J$ Pineal 46: 401-407. [Crossref]

34. Hatzis G, Ziakas P, Kavantzas N, Triantafyllou A, Sigalas P, et al. (2013) Melatonin attenuates high fat diet-induced fatty liver disease in rats. World J Hepatol 5: 160-169. [Crossref]

35. Gonciarz M, Gonciarz Z, Bielanski W, Mularczyk A, Konturek PC et al. (2012) The effects of long-term melatonin treatment on plasma liver enzymes levels and plasma concentrations of lipids and melatonin in patients with nonalcoholic steatohepatitis: a pilot study. J Physiol Pharmacol 63: 35-40. [Crossref]

36. Celinski K, Konturek PC, Slomka M, Cichoz-Lach H, Brzozowski T et al. (2014) Effects of treatment with melatonin and tryptophan on liver enzymes, parameters of fat metabolism and plasma levels of cytokines in patients with non-alcoholic fatty liver disease--14 months follow up. $J$ Physiol Pharmacol 65: 75-82. [Crossref]

37. Roth CL, Gebhardt U, Müller HL (2011) Appetite-regulating hormone changes in patients with craniopharyngioma. Obesity (Silver Spring) 19: 36-42. [Crossref]

38. Holmer H, Pozarek G, Wirfält E, Popovic V, Ekman B, et al. (2010) Reduced energy expenditure and impaired feeding-related signals but not high energy intake reinforces hypothalamic obesity in adults with childhood onset craniopharyngioma. $J$ Clin Endocrinol Metab 95: 5395-402. [Crossref]

39. Harz KJ, Müller HL, Waldeck E, Pudel V, Roth C.. (2003) Obesity in patients with craniopharyngioma: assessment of food intake and movement counts indicating physical activity. J Clin Endocrinol Metab 88: 5227-31. [Crossref]

40. Lustig RH, Hinds PS, Ringwald-Smith K, Christensen RK, Kaste SC, et al. (2003) Octreotide therapy of pediatric hypothalamic obesity: a double-blind, placebocontrolled trial. J Clin Endocrinol Metab 88: 2586-92. [Crossref]

Copyright: @2017 Jemel M. This is an open-access article distributed under the terms of the Creative Commons Attribution License, which permits unrestricted use, distribution, and reproduction in any medium, provided the original author and source are credited. 